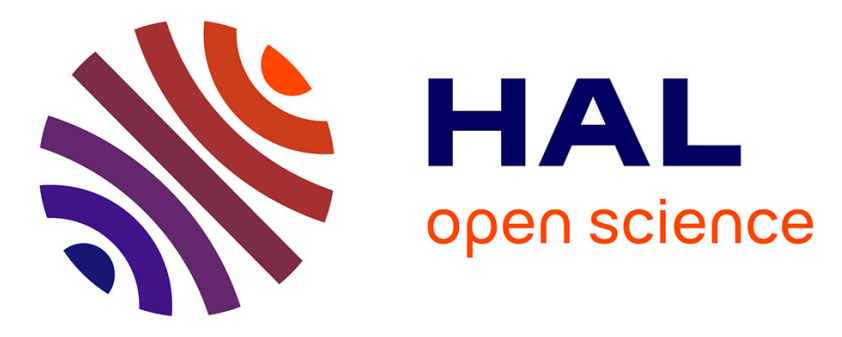

\title{
Synthesis of tin nanocrystals in room temperature ionic liquids
}

Steven Le Vot, Damien Dambournet, Henri Groult, Anh-Tu Ngo, Christophe Petit, Cécile Rizzi, Caroline Salzemann, Juliette Sirieix-Plenet, Olaf J Borkiewicz, Encarnación Raymundo-Piñero, et al.

\section{To cite this version:}

Steven Le Vot, Damien Dambournet, Henri Groult, Anh-Tu Ngo, Christophe Petit, et al.. Synthesis of tin nanocrystals in room temperature ionic liquids. Dalton Transactions, 2014, 43, pp.18025-18034. 10.1039/C4DT02289K . hal-01102801

\section{HAL Id: hal-01102801 https: / hal.sorbonne-universite.fr/hal-01102801}

Submitted on 13 Jan 2015

HAL is a multi-disciplinary open access archive for the deposit and dissemination of scientific research documents, whether they are published or not. The documents may come from teaching and research institutions in France or abroad, or from public or private research centers.
L'archive ouverte pluridisciplinaire HAL, est destinée au dépôt et à la diffusion de documents scientifiques de niveau recherche, publiés ou non, émanant des établissements d'enseignement et de recherche français ou étrangers, des laboratoires publics ou privés. 


\title{
Synthesis of tin nanocrystals in room temperature ionic liquids
}

\author{
Steven Le Vot, ${ }^{\mathrm{a}, \mathrm{b}, \mathrm{c}, \mathrm{d}, \uparrow}$ Damien Dambournet, ${ }^{\mathrm{a}, \mathrm{b}}$ Henri Groult, ${ }^{\mathrm{a}, \mathrm{b}}$ Anh-tu Ngo, ${ }^{\mathrm{c}, \mathrm{d}}$ \\ Christophe Petit, ${ }^{c, d}$ Cécile Rizzi, ${ }^{\text {a,b }}$ Caroline Salzemann, ${ }^{\text {c,d }}$ Juliette Sirieix-Plenet, ${ }^{\text {a,b }}$ \\ Olaf J. Borkiewicz, ${ }^{\mathrm{e}}$ Encarnación Raymundo-Piñero, ${ }^{\mathrm{f}}$ Laurent Gaillon, ${ }^{\mathrm{a}, \mathrm{b}}$
}

\begin{abstract}
The aim of this work was to investigate the synthesis of tin nanoparticles (NPs) or tin/carbon composite, in room temperature ionic liquids (RTILs), that could be used as structured anode materials for Li-ion batteries. An innovative route for the synthesis of Sn nanoparticles in such media was successfully developed. Compositions, structures, sizes and morphologies of NPs were characterized using high-energy X-ray diffraction (HEXRD), X-ray photoelectron spectroscopy (XPS) and high-resolution transmission electron microscopy (HRTEM). Our findings indicated that i) metallic tetragonal $\beta$-Sn was obtained and ii) the particles size could be tailored by tuning the nature of the RTILs, leading to nano-sized spherical particles with diameter ranging from 3 to $10 \mathrm{~nm}$ depending on synthesis conditions. In order to investigate carbon composite materials for Li-ions batteries, Sn nanoparticles were successfully deposited on the surface of multi-wall carbon nanotubes (MWCNT). Moreover, electrochemical properties have been studied in links with structural study of the nanocomposites. The poor electrochemical performances as negative electrode in Li-ion battery is due to a significant amount of RTIL trapped within the pores of the nanotubes as revealed by XPS investigations. This dramatically affected the gravimetric capacity of the composites and limited the diffusion of lithium. The findings of this work, however offer valuable insights into the exciting possibilities for synthesis of novel nano-sized particles and/or alloys (e.g. Sn-Cu, Sn-Co, Sn$\mathrm{Ni} .$. ) and the importance of carbon morphology in metal pulverization during alloying/dealloying process as well as prevention of ionic liquid trapping.
\end{abstract}

\footnotetext{
${ }^{a}$ Sorbonne Universités, UPMC Univ Paris 06, UMR 8234, PHENIX, 4 place Jussieu F-75005, Paris, France.

${ }^{b}$ CNRS, UMR 8234, PHENIX, F-75005, Paris, France.

${ }^{c}$ Sorbonne Universités, UPMC Univ Paris 06, UMR 8233, MONARIS, 4 place Jussieu F-75005, Paris, France

${ }^{d}$ CNRS, UMR 8233, MONARIS, 4 place Jussieu, F-75005, Paris, France.

${ }^{e} \mathrm{X}$-ray Science Division, Advanced Photon Source, Argonne National Laboratory, Argonne, Illinois 60439, United States

${ }^{f}$ CEMHTI - CNRS Orléans, site haute température, 1D Avenue de la Recherche Scientifique, 45071 Orléans Cedex 02, France.

$\dagger$ Corresponding author: S. Le Vot. steven.levot@gmail.com
}

\section{Introduction}

Tackling issues related to the environmental and energy stewardship has become of late a very significant challenge for the electrochemical community. Over the past decade, a tremendous effort has been undertaken to design, synthesize and optimize new electrode materials that could be suitable for use in next-generation energy storage devices, e.g. Li-ion batteries ${ }^{1-7}$. Owing to their exceptionally high theoretical capacity (993 mAh g ${ }^{-1}$ vs. $372 \mathrm{mAh} \mathrm{g}^{-1}$ for commercial graphite electrodes), Sn-based compounds were identified as very promising candidates for anode materials ${ }^{8-16}$. Unfortunately, due to detrimental volume change during charge/discharge cycles, that induces high mechanical stress leading to electrode failure, technological applicability of these materials is highly limited ${ }^{8}$. It is strongly believed that reducing the size of $\mathrm{Sn}$ particles to the nanoscale and carefull mixing with an inert element regarding $\mathrm{Li}$ alloying/dealloying reactions will allow to overcome this issue $5,10,11,14$.

Because of the incredible potential of tin and tin oxides, these metal compounds have been widely studied. However, regarding nanoparticles synthesis ${ }^{17}$, the literature devoted for tin derivatives prefers by far physical preparation techniques (chemical vapor deposition, laser ablation, sputtering...) to chemical ones 18. In the early 2000's, Nayral et al. demonstrated the possibility of obtaining $\mathrm{Sn}$ nanoparticles (NPs) with diameter of around $20 \mathrm{~nm}$ by thermal decomposition of $\left[\left[\mathrm{Sn}\left(\mathrm{NMe}_{2}\right)_{2}\right]_{2}\right]$ in anisole ${ }^{18}$. Later, Wang et al. reported synthesis of tin nano-objects with size ranging from 3.5 to $19 \mathrm{~nm}$ under varying experimental conditions ${ }^{19}$. In their study a Phen $\left(\mathrm{SnCl}_{4}\right)$ compound is chemically reduced by $\mathrm{NaBH}_{4}$. Recently, Caballero et al. proved that it was possible to prevent tin agglomeration by using cellulose fibers during $\mathrm{SnCl}_{4}$ reduction by $\mathrm{KBH}_{4}{ }^{20}$. Particles of around 20-30 nm were obtained using these techniques. NPs exhibiting almost identical sizes were also obtained by the reduction of tin acetate with $\mathrm{NaBH}_{4}$. Kwon et al. investigated the influence of three capping agents (hydrobenzamide, trisodium citrate and polyvinyl pyrrolidone) on the properties of synthesized nanoparticles ${ }^{21}$. Chee et al. studied the influence of metallic precursor (tin acetate, tin chloride, tin sulfate and tin ethylhexanoate) on the morphologies and size of NPs ${ }^{22}$. Finally, Kravchyk et al. recently demonstrated that it was possible to prepare stable colloidal suspensions of monodispersed tin nanocrystals with size varying from 9 to 23 $\mathrm{nm}{ }^{23}$. Synthesis was performed in organic media (oleylamine, 
THF) at the temperature of about $200{ }^{\circ} \mathrm{C}$, where oleylamine served as both, solvent and stabilizing agent.

Tin/carbon synthesis has also been studied and reported in the literature due to its possible application as anode material for Li-ion battery, e.g. work by Billaud and coworkers, who reported on $\mathrm{Sn} /$ graphite composite synthesis ${ }^{13,}{ }^{24-26} \cdot \mathrm{SnCl}_{2}$ and/or $\mathrm{SnCl}_{4}$ were reduced in the presence of a carbon source (e.g. KC8) in THF. The reported sizes of the tin nanoparticles varied between 10 and $40 \mathrm{~nm}$. Zhang et al. demonstrated that carbon nanotubes could be selectively decorated with tin nanoparticles deposited inside or outside of the carbon structure 27. In this case $\mathrm{SnCl}_{2}$ was reduced by $\mathrm{NaBH}_{4}$ in ethanol in the presence of nanotubes. Hassoun et al. investigated the behavior of a $\mathrm{Sn} /$ carbon composite prepared by calcination ${ }^{11}$. Very recently, Bresser et al. also reported preparation of tin/carbon composite using annealing process ${ }^{14}$.

All the aforementioned techniques resulted in the formation of nanoparticles of desired properties (structure, size, etc.) but none of them was without the room for improvement. For example, the use of organic solvents can be very detrimental to health and poses environment hazards and should be avoided if possible. In some cases high temperature processes are needed. Capping agents, used to prevent particle aggregation, could be very difficult to remove without alteration of tin nanoparticles size and/or structure and may consequently have a negative effect on the electrochemical performances of Sn-based materials. Moreover, the undesirable formation of tin oxides was observed in nearly all instances. Finally, the reported size of Sn NPs in most cases is larger than $10 \mathrm{~nm}$, where smaller particles would be highly beneficial in many applications. Very interestingly, room temperature ionic liquids (RTILs) are promising solvents that should permit to overcome all these issues. Indeed, RTILs (salts composed of organic cations and inorganic or organic anions) are very convenient media to prepare metallic nanoparticles (NPs) ${ }^{28-37}$. Due to their unique properties, RTILs act not only as good solvents for metallic salts but also as stabilizing agents. They prevent aggregation of freshly synthesized nanoparticles by surrounding them and forming a so-called protective electrosteric layer. Despite its attractiveness, synthesis of nanoparticles in ionic liquid is still in its early stage and most of the reported studies deal with noble metal ( $\mathrm{Au}, \mathrm{Pt}, \mathrm{Ir}, \mathrm{Ru}, \mathrm{Pd} \ldots)$ preparation applied to catalysis ${ }^{32}$. Among the techniques used to prepare NPs ${ }^{17}$, electrodeposition, thermal decomposition, laser ablation, sputtering and chemical reduction are those compatible with the use of ionic liquid. For chemical reduction, in many cases a metal precursor is reduced under pressure by molecular hydrogen ${ }^{32}$. On the other hand, studies using standard chemical reducers that are commonly used for NPs synthesis in aqueous and/or organic media (e.g. sodium borohydride, hydrazine or trisodium citrate) are scarcer $29,30,38-46$.

We report herein an original study investigating formation of Sn NPs through synthesis in several ionic liquids. The purposes of this work can be summarized as follows: (i) to determine experimental conditions leading to the formation of tin nanoparticles; (ii) to investigate the influence of the nature of anions and cations of the RTIL and/or parameters that define the experimental environment on the morphology and size of the nanoparticles; (iii) to synthesize new tin/carbon composite and (iv) to investigate the electrochemical performances of the tin NPs or tin/carbon composite as a structured anode materials for Li-ion batteries.

\section{Chemicals}

All chemicals used (excepted acetone) are stored in a glove box under argon atmosphere. Anhydrous tin(II) chloride $\left(\left(\mathrm{SnCl}_{2}\right)\right.$, Alfa Aesar, 98\%), sodium borohydride $\left(\left(\mathrm{NaBH}_{4}\right)\right.$, Sigma Aldrich, > 98\%) methanol (VWR, 99.8\%), acetone (VWR, technical grade), 1-ethyl-3-methylimidazolium bis(trifluoromethylsulfonyl)imide) (EMIm NTf ${ }_{2}$, 1-butyl-1methylpyrrolidinium bis(trifluoromethylsulfonyl)imide) (BMP $\mathrm{NTf}_{2}$ ), 1-ethyl-3-methylimidazolium dicyanamide (EMIm DCA) and 1-Butyl-1-methylpyrrolidinium dicyanamide (BMP DCA) (Solvionic, 99.5\%) were used "as received" without additional purification. 1-Butyl-3-methylimidazolium bis(trifluoromethylsulfonyl)imide) (BMIm NTf $\mathrm{NT}_{2}$, 1-Dodecyl-3methylimidazolium bis(trifluoromethylsulfonyl)imide) $\left(\mathrm{C}_{12} \mathrm{MIm} \quad \mathrm{NTf}_{2}\right), \quad$ 1-Butyl-2,3-dimethylimidazolium bis(trifluoromethylsulfonyl)imide) (BDMIm NTf N $_{2}$, 1-Butyl-3methylimidazolium tetrafluoroborate $\left(\mathrm{BMIm} \quad \mathrm{BF}_{4}\right)$ and 1Decyl-3- methylimidazolium Bromide $\left(\mathrm{C}_{10} \mathrm{MIm} \mathrm{Br}\right)$ were synthesized in the laboratory ${ }^{47-52}$. The water content of ionic liquid was determined using standard Karl-Fischer method (coulometric titrator titroline KF trace, Schott instruments) and was always inferior to $500 \mathrm{ppm}$. This value of $500 \mathrm{ppm}$ was arbitrarily chosen as a reference because it corresponds to that given by Solvionic (our supplier for commercial RTILs) for their ionic liquids packed under argon. For the tin/carbon composite, multi wall carbon nanotubes (MWCNTs) were used. Multiwalled carbon nanotubes (CCVD, Groupement de Recherches de Lacq, Arkema) with a carbon purity of more than 90 wt $\%$ were oxidized by using nitric acid. In particular, 2 $\mathrm{g}$ of MWCNTs were stirred in $60 \mathrm{~mL}$ of a $10 \mathrm{M} \mathrm{HNO}_{3}$ aqueous solution at $80^{\circ} \mathrm{C}$ during 4 hours. After oxidation the material was extensively washed in water. Finally it was dried overnight at $120^{\circ} \mathrm{C}$. For electrochemical testing LP30 electrolyte $(1 \mathrm{M}$ $\mathrm{LiPF}_{6}$ in ethylene carbonate: dimethyl carbonate EC:DMC (1:1) solution) (Merck), acetylene black and polyvinylidene difluoride (PVDF) were used as received.

\section{Synthesis of Sn nanoparticles in pure ionic liquids}

NPs were prepared by chemical reduction method in ionic liquid using a procedure derived from an existing method of synthesis of metallic nanoparticles in organic solvent ${ }^{17,43-45}$. In this process $\operatorname{tin}(\mathrm{II})$ and chloride $\left(\mathrm{SnCl}_{2}\right)$, sodium borohydride $\left(\mathrm{NaBH}_{4}\right)$ were used as metallic precursor and reducing agent, respectively, whereas ionic liquid itself acted as the stabilizing agent. In order to avoid oxygen and moisture contamination, all experiments were performed in a glove box under an argon atmosphere. In a typical experiment, $7.6 \mathrm{mg}$ of anhydrous $\mathrm{SnCl}_{2}$ were dissolved in $1 \mathrm{ml}$ of ionic liquid (solution A). At the same time, $15.2 \mathrm{mg}$ of $\mathrm{NaBH}_{4}$ were dissolved in $1 \mathrm{ml}$ of the same ionic liquid (solution B). Pillboxes (A and B) were carefully sealed and underwent an ultrasonic treatment for 1 hour. Then, the two solutions were stirred (500 RPM) for $16 \mathrm{~h}$ 30. Finally, solution B was quickly added to solution A (still under stirring) leading to the immediate formation of a deep black solution indicating that nanoparticles were formed. Stirring was maintained for $6 \mathrm{~h}$, after what solution was stored into the glove box.

\section{Nanoparticles isolation}

\section{Experimental}


Sn nanoparticles were isolated by centrifugation (3500 RPM) until the ionic liquid supernatant was clear. According to synthesis conditions (e.g. tin concentration, volume, nature of ionic liquid) this stage used to take 40 minutes but it could last longer (several hours). Then Sn nanoparticles were rinsed with acetone and were isolated by centrifugation (3500 RPM) for 5 min (four times). Finally, a last rinsing was performed followed by centrifugation at $10000 \mathrm{RPM}$ for $5 \mathrm{~min}$ whereupon tin nanoparticles were dried under vacuum overnight. Sn nanoparticles under solid form can be easily dispersed in methanol without altering their initial properties.

\section{Nanoparticles characterizations}

Sizes, size dispersions and morphologies of synthesized nanoparticles were observed by transmission electron microscopy (TEM) using a JEOL 1011 microscope at an accelerating voltage of $100 \mathrm{kV}$. High-resolution TEM (HRTEM) images were obtained with an HRTEM JEOL 2010 operating at an acceleration voltage of $200 \mathrm{kV}\left(\mathrm{LaB}_{6}\right)$. Same grids were used for both microscopes. To prepare samples for TEM and HRTEM, $100 \mu \mathrm{l}$ of the NPs suspension (in RTIL) had first to be diluted in $2 \mathrm{ml}$ of methanol under stirring $(90 \mathrm{~min}$, 500 RPM). Prior to this dilution, NPs suspension in RTIL was homogenized by stirring for $30 \mathrm{~min}$. Finally, a drop of the alcoholic solution containing Sn nanoparticles was carefully placed on a carbon coated copper grid. Total scattering measurements $(\lambda \sim 0.1458 \AA)$ were performed at the Advanced Photon Source (Argonne National Laboratory) ${ }^{53,54}$. Diffraction images were integrated within fit2D data analysis program to obtain the one-dimensional diffraction data. Pair distribution functions (PDF), G(r), were extracted from the data using PDFgetX2 software ${ }^{55}$. Refinement of the PDF data was performed using the PDFgui software ${ }^{56}$. The chemical composition of the surface was analyzed by $\mathrm{x}$-ray photoelectron spectroscopy (XPS) on powders of the materials with a VG ESCALAB 250 spectrometer using an Al K $\alpha$ monochromatic source $(15 \mathrm{kV}, 15 \mathrm{~mA})$ and a multidetection analyzer, under $10^{-8} \mathrm{~Pa}$ residual pressure.

\section{Electrochemical testing}

Electrodes were prepared using 80 wt.\% active material, 10 wt. $\%$ acetylene black as the conductive agent, and $10 \mathrm{wt} . \%$ polyvinylidene difluoride (PVDF) as the binder. Active material included Sn/carbon composite (80/20 wt.\%). Swagelok cells were assembled in a glove box under argon atmosphere. Copper, lithium and LP30 solution (see chemicals) were used as the current collector, the negative electrode and the electrolyte, respectively. The galvanostatic charge-discharge curves were performed at room temperature using a potentiostat/galvanostat (VMP3 BioLogic Science Instrument) in the potential range: $0.05-2.0 \mathrm{~V}$.

\section{Results and discussion}

\section{Synthesis of nanoparticles}

Figure 1 summarizes nine combinations of cations and anions that were investigated for $\mathrm{Sn}$ nanoparticles synthesis. These ionic liquids were chosen in order to compare the influence of their physico-chemical properties (hydrophobicity, volume and size of their constituting ions, viscosity...) on the shapes, morphologies and sizes of formed nanoparticles. A first observation is that the nature of the ionic liquid plays a major role during the synthesis. Indeed, despite a high ability to dissolve $\mathrm{SnCl}_{2}$, ionic liquids composed of $\mathrm{DCA}^{-}$anions did not allow the formation of tin nanoparticles. In fact the coordination ability of this anion is too high and prevents the reduction of tin chloride by sodium borohydride which is nevertheless considered as a strong reducing agent (compare to trisodium citrate or $\mathrm{H}_{2}$ for example). This conclusion is comforted by electrochemical studies carried out in our laboratory which demonstrated that a more negative potential was required to reduce $\mathrm{Sn}^{2+}$ ions on a conductive substrate using this $\mathrm{DCA}^{-}$ionic liquid. It can also be noticed that $\mathrm{Sn}^{2+}$ ions were not reduced either using $\mathrm{C}_{10} \mathrm{MIm} \mathrm{Br}$ and thus NPs were never formed with this ionic liquid. Finally, Fig.1 indicates that particles cannot be formed using BDMIm cation with $\mathrm{NTf}_{2}^{-}$anion. Even if mechanisms for the syntheses of nanoparticles in ionic liquids are still unclear, it has been postulated in the literature that carbene intermediates should likely be involved in the reaction process when imidazolium cations are used 35, 37. Our findings are relevant with this hypothesis. Indeed, if carbon in position 2 of the imidazolium ring is blocked by the presence of a methyl group then no carbene intermediate can be formed and consequently no nanoparticle can be synthesized. Fig. 1 also shows that all the other attempts using imidazolium-based ionic liquid with labile hydrogen in position $\mathrm{C}_{2}$ were successful, comforting the hypothesis of a carbene intermediate. However, syntheses with

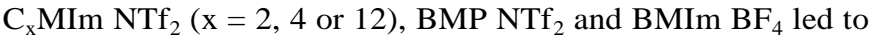
the formation of tin nanoparticles.

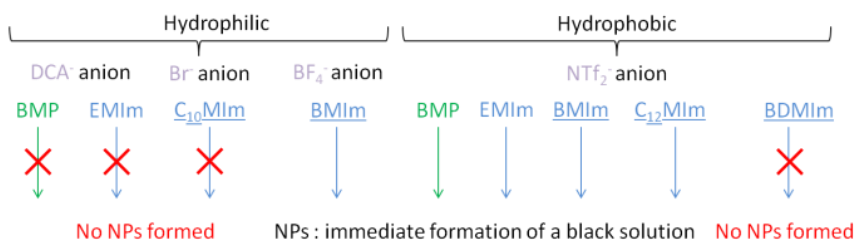

Fig.1 Scheme of the nine combinations of cations and anions that were investigated for $\mathrm{Sn}$ nanoparticles synthesis. Anions (purple) were associated to imidazolium (blue) or pyrrolidinium (green) cations. Underlined cation means that ionic liquid was synthesized in our laboratory, else they are commercial ones.

\section{Characterisations of nanoparticles}

Atomic structure of as prepared compounds was investigated using the total scattering method. Fourier transformation of diffraction data (Inset Fig. 2) yielded the pair distribution function, G(r) ${ }^{57}$. PDF provided an accurate atomic structural resolution by using both Bragg and diffuse intensities thus probing structural features independently of the crystalline nature of the sample. The obtained PDF data representing an histogram of all the atom-atom distances within a sample was refined using tetragonal metallic tin (SG: $\mathrm{I}_{1} / \mathrm{amd}$ ) as structural model. The result displayed in figure 2 showed a good agreement between the model and the experimental data with a good reliability factor $\mathrm{R}_{\mathrm{w}}$ of $21 \%$. The extracted unit cell parameters, $\mathrm{a}=5.829(1)$ and $\mathrm{b}=3.185(1) \AA$, agreed well with literature data. This confirmed the stabilization of metallic tin. The absence of features in the residual curve indicated a priori, the absence of impurities at least related to tin. TEM images presented on figure 3 showed the isolation of nanoparticles exhibiting a mean diameter of around $7 \mathrm{~nm}$ which are quite homogeneous in size. High Resolution TEM revealed that the 
nanoparticles are highly crystalline (Fig 3d). This is in good agreement with PDF analysis which showed defined features up to $5 \mathrm{~nm}$.

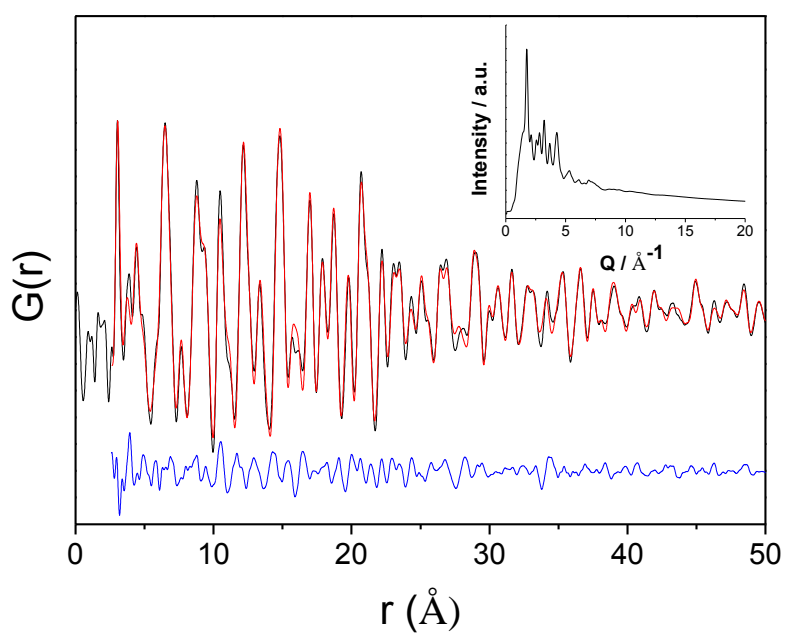

Fig. 2 Experimental (black) and calculated (red) pair distribution functions (PDF) obtained from high-energy x-ray scattering data (Inset) for tin nanoparticles synthesized in EMIm NTf 2 . Difference between experiment and calculation is also shown (blue). Reliability factor Rw was found to be $21 \%$.
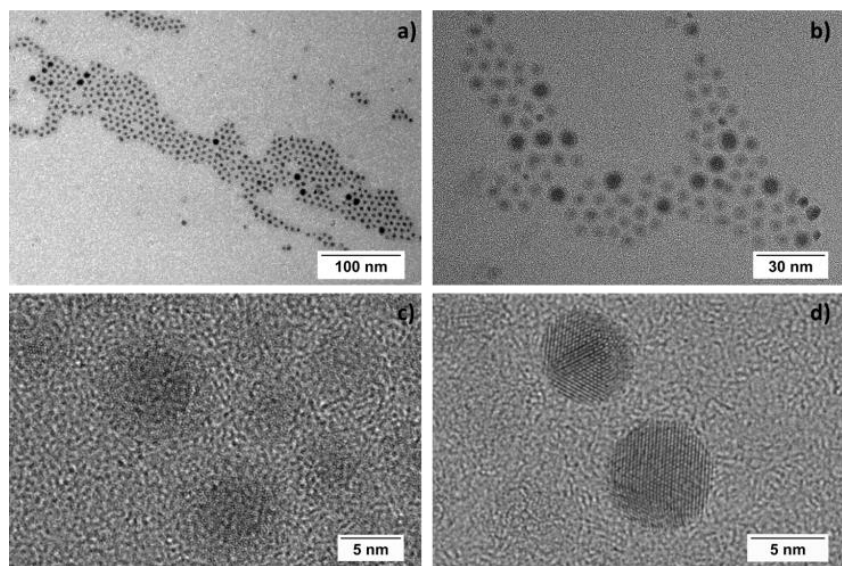

Fig. 3 TEM (a-b) and HRTEM (c-d) images of Sn nanoparticles synthesized in EMIm $\mathrm{NTf}_{2}$.

Careful observations also revealed that some particles (Fig. 3b) and 3d) are surrounded by a thin external layer of approximately $2 \mathrm{~nm}$. This observation can be correlated with the PDF features located at low r-region, which might indicate the residual presence of organic compounds (from precursors and/or ionic liquid) at the surface. It should be noted that even if PDF showed that $\mathrm{Sn}$ nanoparticles were prepared in a single phase, it cannot fully excluded the presence of a thin layer of Sn oxide. Nevertheless, it is assumed that this layer is rather made of compounds such as $\mathrm{NaCl}$ issued from the reactants, $\mathrm{SnCl}_{2}$ and $\mathrm{NaBH}_{4}$ and/or of ionic liquid solvent which may both strongly interact with nanoparticles during synthesis and that are difficult to remove from the surface of the nanoparticles. Nevertheless, very well defined individual nanoparticles that seem to be spherical and well organized were also observed. Fig. 3d shows nanoparticles exhibiting a mean diameter of around $7 \mathrm{~nm}$ which are quite homogeneous in size with high crystallinity.

\section{Influence of water during synthesis}

Figure 4 shows representative TEM images of tin nanoparticles synthesized in the hydrophobic EMIm $\mathrm{NTf}_{2}$ ionic liquid. When a dry ionic liquid (i.e. water content $<500 \mathrm{ppm}$ ) was used nice individual nanoparticles are observed (Fig. 4a and 4c). Contrariwise, when a very small amount of water is added to the same ionic liquid in order to reach $5000 \mathrm{ppm}$, tin nanoparticles synthesis was dramatically affected (Fig. 4b and 4d). Consequently, large aggregates were formed very likely because water inhibits the capping properties of ionic liquid toward tin's surface. This observation was confirmed performing a synthesis using a water/ionic liquid mixture $(50 / 50 \mathrm{v} / \mathrm{v} \%)$. In this latter case, $\mathrm{SnCl}_{2}$ was dissolved in pure hydrophobic ionic liquid (EMIm $\mathrm{NTf}_{2}$ ) and $\mathrm{NaBH}_{4}$ in water. When the two solutions were mixed together, $\mathrm{Sn}^{2+}$ were reduced but growth of nanoparticles was never stopped leading to the formation of a big ( $4 \mu \mathrm{m}$ large) "pebble" of tin. Figure 4 illustrates well the absolute necessity to control the experimental conditions. As a consequence of these early observations, all syntheses were performed into a glove box under argon atmosphere. When ionic liquids were synthesized in our laboratory, then they were dried using a lyophilizer till a value inferior to $500 \mathrm{ppm}$ was reached.

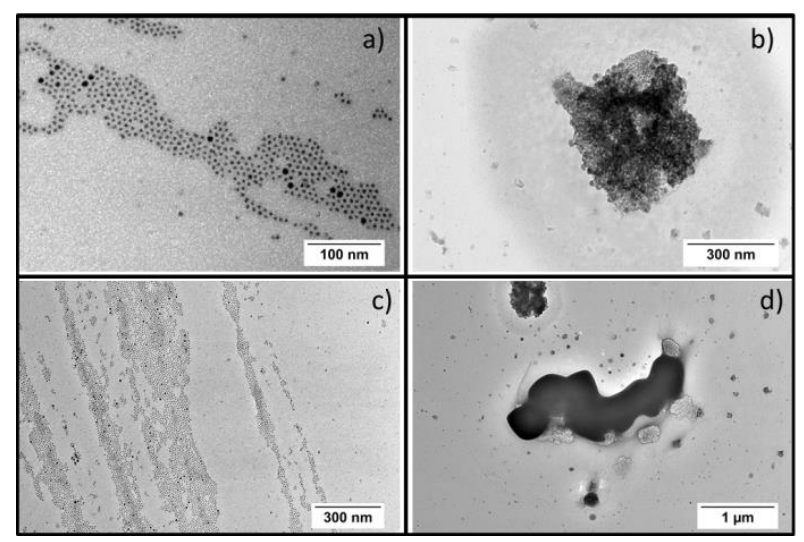

Fig. 4 TEM images of Sn nanoparticles synthesized in: a) and c) "dry" EMIm $\mathrm{NTf}_{2}$ and b) and d) EMIm $\mathrm{NTf}_{2}+5000 \mathrm{ppm} \mathrm{H}_{2} \mathrm{O}$.

\section{Evolution of nanoparticles with time}

Figure 5 shows TEM images of three grids corresponding to solution aged for 6 hours, 2 and 9 days after the synthesis (i.e. time 0 when solution B was added to solution A). In all cases, individual nanoparticles of around $7 \mathrm{~nm}$ were obtained meaning that nanoparticles were stable during at least 9 days. Ionic liquid prevented growth of nanoparticles ${ }^{31}$. It is important to remind here, that the purpose of this work was to develop new nanostructured anode materials for lithium ion batteries and thus a longer "colloidal" stability was not required. In order to be reproducible when samples were compared, it was decided, for the following experiments, to prepare TEM grids 2 days after the synthesis. 


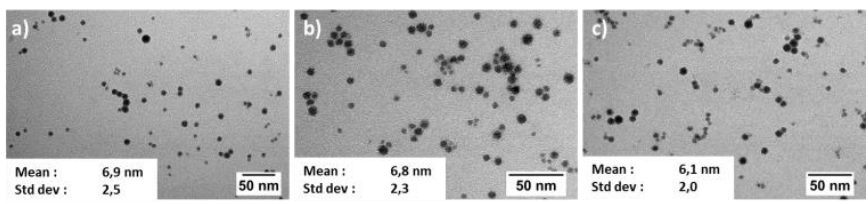

Fig 5 TEM images of $\mathrm{Sn}$ nanoparticles synthesized in EMIm $\mathrm{NTf}_{2}$. Grids prepared: a) 6 hours, b) 2 days and c) 9 days after the synthesis.

\section{Influence of ionic liquid used for Sn nanoparticles synthesis}

As it has already been discussed above (Fig.1) nanoparticles synthesis is strongly affected by the ionic liquid that acts both as solvent and stabilizing agent ${ }^{31,32}$. Huge advantages of ionic liquid are their tunability and the infinite number of anion/cation combinations that can be chosen. It was thus decided to investigate the influence of several ionic liquid exhibiting very different properties (hydrophobicity, viscosity, size of constituting ions, amount of polar/non polar domains...) on the synthesized nanoparticles. It is now widely accepted in literature that ionic liquids and especially imidazolium-based ionic liquids consist in organized structures (3D arrangement) rather than isolated anions and cations $31,32,58,59$. As a consequence, media is not homogeneous and polar and nonpolar nano-regions are present. Several examples in the literature demonstrated that ionic precursors dissolved in the polar domains whereas neutral precursors would prefer non polar domains ${ }^{60,61}$. By varying the length of the alkyl chain of the imidazolium it was possible to change the amount of polar/non-polar nano-domains, a longer chain increasing proportion of non-polar region $59,62,63$. In a first experiment, influence of the alkyl chain lenght of three 1-Alkyl-3methylimidazolium bis(trifluoromethylsulfonyl)imide, $\mathrm{C}_{\mathrm{x}} \mathrm{MIm}$ $\mathrm{NTf}_{2}, \mathrm{x}=2,4$ and 12) was investigated. Figure 6 shows size distributions of three representative samples for which $\mathrm{Sn}$ nanoparticles were synthesized in EMIm NTf $\mathrm{NMIm}_{2}, \mathrm{NTf}_{2}$, and $\mathrm{C}_{12} \mathrm{MIm} \mathrm{NTf}$. Sn nanoparticles of 6.8, 7.3 and $7.0 \mathrm{~nm}$ were respectively observed by TEM. Size of the nanoparticles was not affected by the length of the alkyl chain of the imidazolium cation indicating, as expected, tin metallic precursor $\left(\mathrm{SnCl}_{2}\right)$ being "ionic", that it dissolved preferentially in polar regions 60 , 61. This conclusion is in good agreement with conclusions of studies dealing with $\mathrm{Ir}$ and $\mathrm{Ru}$ NPs syntheses using $\mathrm{H}_{2}$ under reduced pressure as the reducing agent for several ionic and neutral metallic precursors ${ }^{60,61}$. It can also be noticed on figure 6 that more particles were present on the TEM grid as the number of carbons in the chain decreased. This can be explained by the fact that dissolution of tin salts was better in EMIm $\mathrm{NTf}_{2}$ than in $\mathrm{BMIm} \mathrm{NTf}_{2}$ and $\mathrm{C}_{12} \mathrm{MIm} \mathrm{NTf}_{2}$. Indeed volume of polar domains increases when alkyl chain length decreases.
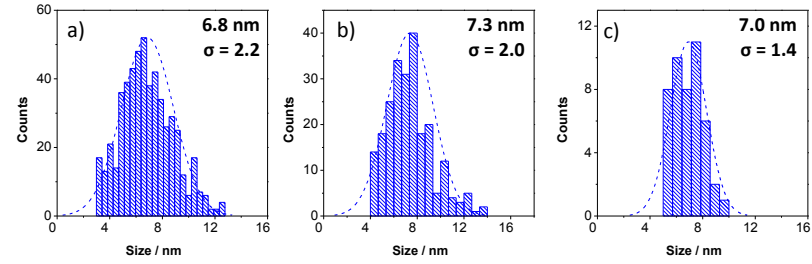

Fig 6 Size distributions from TEM observations of tin nanoparticles synthesized in a) EMIm NTf 2 , b) BMIm NTf 2 and c) $\mathrm{C}_{12} \mathrm{MIm} \mathrm{NTf}_{2}$.
Volume of the polar domain of an ionic liquid can be change varying the size of the anion ${ }^{32}$. As mentioned on Fig. 1, $\mathrm{DCA}^{-}$ and $\mathrm{Br}^{-}$anions did not allow to form nanoparticles. Tin syntheses with $\mathrm{BF}_{4}^{-}$and $\mathrm{NTf}_{2}^{-}$anions were compared using the same (BMIm) imidazolium cation. It can be noticed that size of nanoparticles was strongly affected by the nature of the anion (Fig. 7). When $\mathrm{BF}_{4}^{-}$anion $\left(\mathrm{V}=53 \mathrm{~cm}^{3} \mathrm{~mol}^{-1}\right)$ was used nanoparticles of $3.6 \mathrm{~nm}$ were obtained whereas their size increased to $7.3 \mathrm{~nm}$ with $\mathrm{NTf}_{2}^{-}$anion $\left(\mathrm{V}=159 \mathrm{~cm}^{3} \mathrm{~mol}^{-1}\right)^{64-67}$. Ratio of molecular volumes of anions is 3 and this of nanoparticles sizes is around 8 (assuming that NPs are spheres and considering their volumes) indicating that the relationship between the two parameters was not linear. In case of $\mathrm{BF}_{4}{ }^{-}$ anions, growth limitation of nanoparticles could result from higher viscosity and/or be a consequence of stronger interaction between smaller anions (compare to $\mathrm{NTf}_{2}$ ) and tin clusters. However, it was obvious that, using our experimental conditions, size of nanoparticles increased with the molecular volume of the anion (or anion aggregates considering that ionic liquid are $3 \mathrm{D}$ organized structures). From this conclusion, it can reasonably be assumed that nanoparticles are positively charged and that the first stabilization layer consists of anionic species 68. This confirms the role of passivating agent of the ionic liquid.
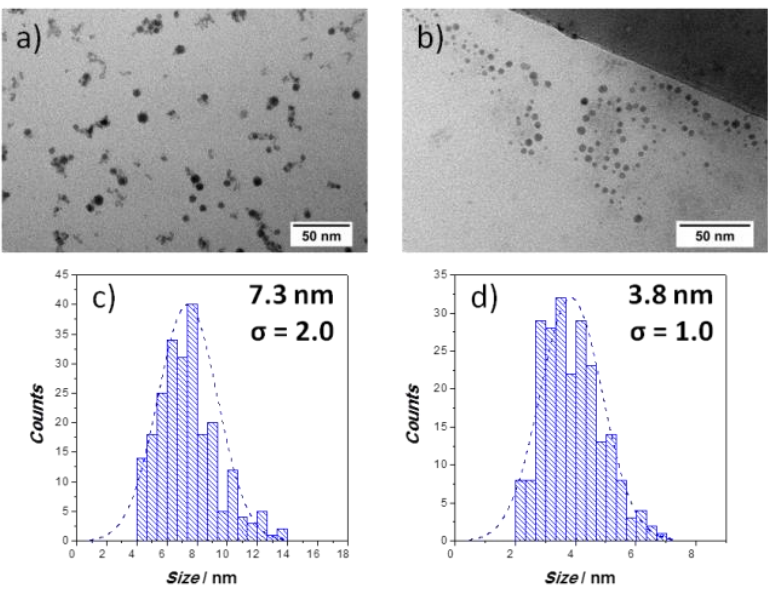

Fig. 7 TEM images of Sn nanoparticles synthesized in a) BMIm $\mathrm{NTf}_{2}$ and b) $\mathrm{BMIm}_{\mathrm{BF}}$. c) and d) size distributions for the two samples a) and b) respectively.

Pyrrolidinium-based ionic liquid are very interesting for electrochemical applications ${ }^{3}$. In that way, Sn nanoparticles synthesis was also investigated in $\mathrm{BMP} \mathrm{NTf}_{2}$. Figure 8 shows very nice individual nanoparticles which seems to be a little bit more faceted (nearly cubic for some of them) than when imidazolium-based ionic liquid was used. Analysis of several TEM images revealed that mean diameter of formed nanoparticles was $8.6 \mathrm{~nm}$ ( $\mathrm{std} \mathrm{dev}=1.5 \mathrm{~nm}$ ) which was higher than the size $(7.3 \mathrm{~nm})$ obtained with imidazolium-based ionic liquid (BMIm $\mathrm{NTf}_{2}$ ). Moreover, synthesis with pyrrolidinium cation led to the formation of tin nanoparticles with narrow size distribution ranging from 6 to $12 \mathrm{~nm}$. One could notice that ILs composed of BMP cation produced relatively monodisperse particles being different from the cases using ILs containing imidazolium cation as a component. Mechanisms for the syntheses of nanoparticles in ionic liquids are still unclear. However, it has been postulated in the literature that carbene intermediates should likely be involved in the reaction process 
when imidazolium cations are used whereas this is not the case for pyrrolidinium cations 35,37 . These different formation pathways very likely influence dispersion of tin nanoparticles.

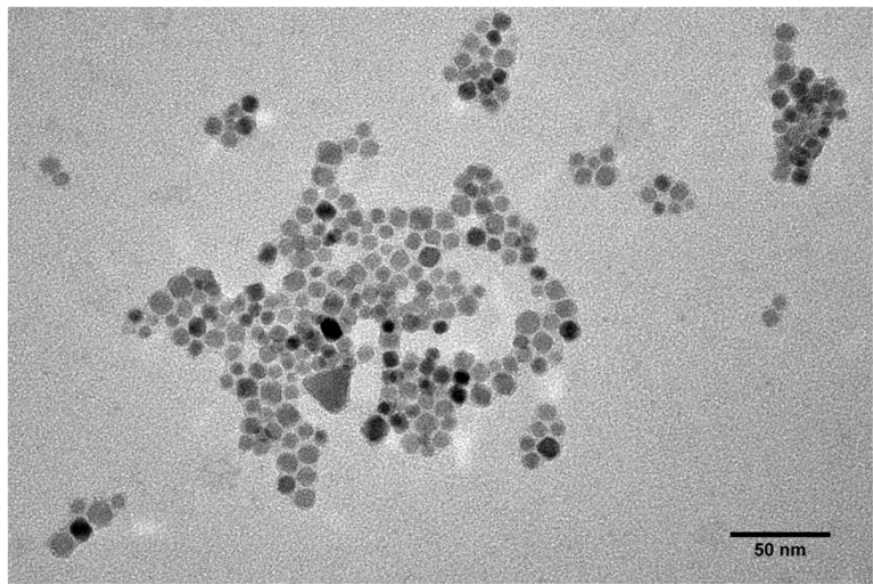

Fig. 8 TEM image of Sn nanoparticles synthesized in BMP $\mathrm{NTf}_{2}$.

\section{Preparation of a tin/carbon composite}

Tin cannot be practically used alone as an electrode material for a lithium battery electrode ${ }^{8}$. In that way carbonaceous compounds are mixed with tin to ensure electrical conductivity and above all mechanical stability of the electrode ${ }^{14}$. In order to synthesize a tin/carbon composite, multi-wall carbon nanotubes (MWCNTs) were added to solution $\mathrm{A}$ which also contained tin chloride precursor before adding $\mathrm{NaBH}_{4}$ reducer (solution B). TEM analysis (Fig. 9) revealed that Sn nanoparticles could be successfully deposited on the MWCNTs surface.

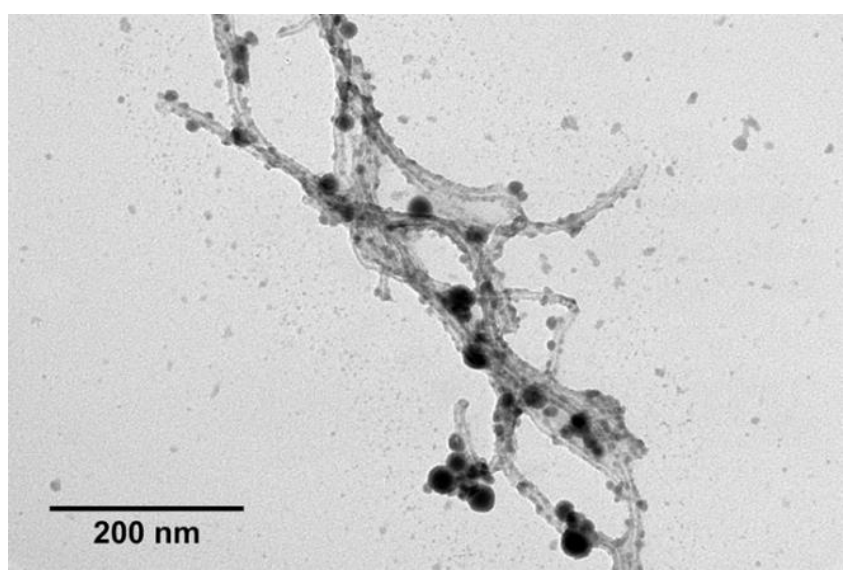

Fig. 9 TEM images of Sn nanoparticles synthesized in the presence of MWCNTs in BMP NTf $(a$ and $b$ are pictures from the same sample).

\section{Characterization of tin/carbon composite}

In order to determine the chemical composition of this composite XPS analyses were carried out. At this point, it is important to remind that a complex composite (see experimental part) is analyzed and that following observation and conclusions cannot be transposed for single tin nanoparticles presented earlier in this study (Figs. 3 to 8 ). Figure 10 shows the survey spectra recorded for the
Sn/MWCNTs compound which is characterized by the presence of Sn 3d (between 482 and $502 \mathrm{eV})$ and C 1s $(285 \mathrm{eV})$ contributions. Nevertheless, S 1s $(170 \mathrm{eV}), \mathrm{F} 1 \mathrm{~s}(685 \mathrm{eV}), \mathrm{Cl}$ $2 \mathrm{p}(200 \mathrm{eV})$ and $\mathrm{Na} \mathrm{1s} \mathrm{(1072} \mathrm{eV)} \mathrm{contributions} \mathrm{could} \mathrm{also} \mathrm{be}$ noticed. It means that ionic liquid (sulfur and fluorine) and contaminants from precursors (sodium and chloride) strongly interacted with tin and/or carbon nanotubes and were very difficult to remove. Due to their geometric structures it was also very likely that a significant amount of ionic liquid was trapped within the pores of the MWCNTs. The analysis of the high resolution spectra of the $\mathrm{Sn}$ region (data not shown) has revealed the presence of metallic tin unequivocally demonstrated by the contribution from the $\operatorname{Sn} 3 \mathrm{~d}_{5 / 2}$ at $484.9 \mathrm{eV}$. Diffraction pattern for the Sn/MWCNTs composite obtained from high-energy $\mathrm{x}$-ray diffraction experiments (data not shown) also confirmed the presence of metallic tetragonal tin $(\beta-\mathrm{Sn})$. Contribution observed at $486.5 \mathrm{eV}$ might be attributed to the presence of $\mathrm{Sn}-\mathrm{Cl}$ bond in a $\mathrm{SnCl}_{2}$ compound, which is consistent with the presence of the $\mathrm{Cl} 2 \mathrm{p}$ peak $(200.4 \mathrm{eV})$ on the core level spectra of chlorine. Furthermore, the presence of oxidized tin species (e.g., $\mathrm{SnO}$ or $\mathrm{SnO}_{2}$ ) is very likely considering the experimental conditions used in this work. Indeed an unavoidable oxide layer is formed as soon as electrode is in contact with ambient air. Moreover Sn-O might arise from the interaction between tin and the functional groups of MWCNT. The peak observed at $487.4 \mathrm{eV}$ is in very good agreement with the presence of $\mathrm{Sn}-\mathrm{O}$ bounds. This also agrees with, the $\mathrm{O} 1 \mathrm{~s}$ peak observed at $532.5 \mathrm{eV}$, which might be attributed to a thin oxide film present at the electrode surface.

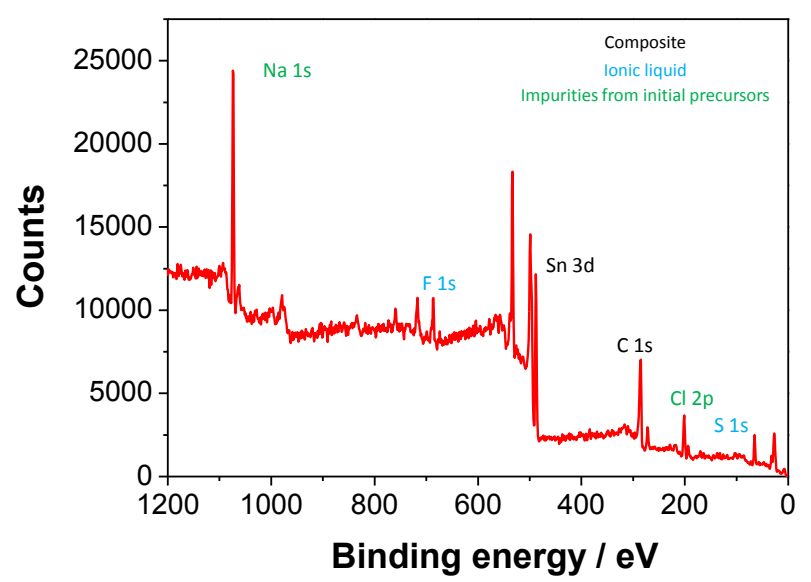

Fig. 10 XPS survey spectra of Sn/MWCNT composite shown in Fig. 9. "In-situ" synthesis in BMP NTf 2 .

\section{Electrochemical behavior of tin/carbon composite}

Preliminary electrochemical characterizations were performed on Sn/MWCNTs composite tested as a negative electrode using a Swagelok® type cell. The electrochemical reaction of Sn vs. Lithium is based on an alloying/de-alloying process which theoretically give rise to the formation of $\mathrm{Li}_{4.4} \mathrm{Sn}$ according to (eq 1)

$\mathrm{Li}_{4.4} \mathrm{Sn} \leftrightarrow \mathrm{Sn}+4.4 \mathrm{Li}^{+}+4.4 \mathrm{e}^{-}$

The expected theoretical capacity based on the formation of $\mathrm{Li}_{4.4} \mathrm{Sn}$ is $869 \mathrm{mAh} \mathrm{g}^{-1}$. Typical discharge/charge curves of 
$\mathrm{Sn} / \mathrm{MWCNT}$ s composite obtained at a rate of $\mathrm{C} / 20$ (i.e. discharge/charge in 20 hours) are shown in Figure 11. The first discharge showed that the composite is electrochemically active leading to a final capacity of $450 \mathrm{mAh} / \mathrm{g}$. Nevertheless, this value is well below the expected theoretical capacity. Thereafter, the first charge capacity dropped to around 150 $\mathrm{mAh} / \mathrm{g}$ showing that a significant amount of lithium remains trapped within the electrode. The poor performances (capacity and cyclability) can be assigned to the presence of residual impurities coming from the synthesis particularly the occurrence of ionic liquid trapped inside the pores of the nanotubes. To summarize, preliminary electrochemical characterization showed that the residual impurities significantly impact the reactivity of the composite vs. lithium. For instance, the calculation of the first discharge capacity (450 $\mathrm{mAh} / \mathrm{g}$ ) was done in considering the total mass of the electrode material, i.e. including inert constituents having no electrochemical activity vs. $\mathrm{Li}^{+}$insertion/extraction (notably ionic liquid, MWNT). Consequently, the data deduced from Fig. 11 are underestimated and larger values should be obtained in considering only the mass of Sn. Therefore, efforts should focus on the material purification. Moreover, we could expect to have better performances by using smaller carbonaceous source such as SWNT to avoid trapping of the ionic liquid within the carbon matrix. Finally, due to the use of nano-scaled compounds, the shape of C/Sn-nano composites as well as the quality of the carbonaceous coating should have a significant impact on the electrochemical performances of the battery. Indeed, as reported above, such a coating ensures electrical conductivity and above all mechanical stability of the electrode.

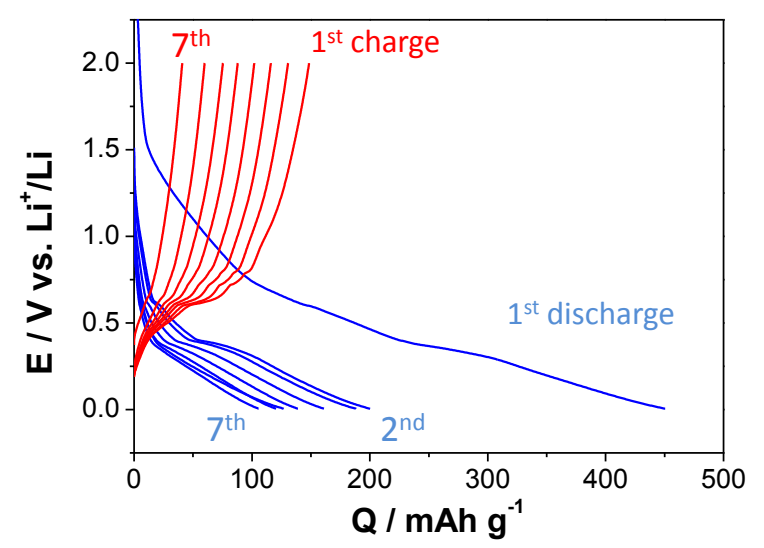

Fig. 11 Voltage profile obtained upon charge/discharge of $\mathrm{Sn} / \mathrm{MWCNTs}$ composite characterized in Fig. 9 and 10. Swagelok® type cell were cycled between 0.05 and $2 \mathrm{~V}$ at $50 \mathrm{~mA} \mathrm{~g}^{-1}$.

The major aim of this work was to develop a new experimental setup allowing the synthesis of metallic tin nanoparticles that can be used as structured anode in a lithium-ion battery ${ }^{5}$. To the best of our knowledge this is the first time that tin nanoparticles synthesis was achieved in ionic liquid. This original study opens many possibilities to move toward Sn-M $(\mathrm{M}=\mathrm{Ni}, \mathrm{Cu}, \mathrm{Co} \ldots)$ nano-alloys synthesis using a simple chemical reduction method. Our findings indicated that the size of $\mathrm{Sn}$ particles could be tailored by tuning the nature of the RTILs, leading to nano-sized spherical particles ranging from 3 to $10 \mathrm{~nm}$. Moreover, $\mathrm{Sn}$ nanoparticles could be successfully deposited on the MWCNTs surface. Future works build on this report should aim to find more appropriate carbon morphology that will prevent the trapping of ionic liquid in order to enhance electrochemical properties targeting a battery application. This study also highlighted the importance to control experimental setup during all stages of the process (i.e. from the early preparation of the synthesis to the fabrication of a composite electrode). This work also brought into the light that rinsing and isolation of nanoparticles were very challenging tasks. Indeed, protocols had to avoid metal oxidation and aggregation and thus almost forbad the use of water or thermal treatment for example. Moreover, rinsing solvent should be compatible with the ionic liquid involving difficulties to harmonize the procedure as solubility in solvents differed from a given RTIL to another.

\section{Conclusion}

An innovative route for the synthesis of Sn nanoparticles in RTILs was successfully developed. To the best of our knowledge, this is the first time that such a modus operandi was successfully elaborated to obtain nano-sized tin using ionic liquids. RTIL acted as solvent and capping agent for the synthesis of $\mathrm{Sn}$ nanoparticles. High energy $\mathrm{x}$-ray diffraction analyses seemed to indicate that the tetragonal $(\beta-\mathrm{Sn})$ phase was pure and consequently that only metallic tin was formed. However, TEM images showed the presence of an external layer surrounding some of the nanoparticles. The composition of this layer remains unclear at this time. It was very likely that this layer was composed of organic compounds from solvent (ionic liquid) and/or precursors $\left(\mathrm{NaBH}_{4}\right.$ and $\mathrm{SnCl}_{2}$ ). Using our experimental conditions, size of the nanoparticles was independent (or at least no significantly affected as regards the targeted application) of the nature of the cation whereas smaller was the anion smaller were the nanoparticles. Thus, nanoobjects ranging from 3 to $10 \mathrm{~nm}$ could be obtained with relative homogeneous size dispersion. Moreover, syntheses had to be carried out with dry ionic liquid in a glove box under argon atmosphere to prevent aggregation phenomenon. The nanoparticles formed in this work could be used to replace graphite as an anode in a Li-ion battery and a $\mathrm{Sn} /$ carbon composite was tested. Tin nanoparticles can be successfully deposited on the surface of nanotubes. Nevertheless, it was found that MWCNTs morphology was not appropriate. Indeed, a significant amount of RTIL was trapped within the pores of the nanotubes, lowering the gravimetric capacity and limiting the diffusion of lithium. More appropriate carbon morphology should prevent the trapping of ionic liquid and thus enhanced electrochemical properties could be expected.

\section{Acknowledgements}

This work was supported by the LabEx MiChem part of French state funds managed by the ANR within the Investissements d'Avenir programme under reference ANR-11-IDEX-0004-02. The authors would like to thank the "Centre National de la Recherche Scientifique" (CNRS) for financial support of this work. Work done at Argonne and use of the Advanced Photon Source, an Office of Science User Facility operated for the U.S. Department of Energy (DOE) Office of Science by Argonne National Laboratory, were supported by the U.S. DOE under Contract No. DE-AC02-06CH11357. The authors also gratefully thank S. Casale (UPMC) for HRTEM observations.

\section{References}


26. D. Billaud, L. Balan, R. Schneider and P. Willmann, Carbon, 2006, 44, 2508-2515.

1. P. Poizot, S. Laruelle, S. Grugeon, L. Dupont and J. M. 27. Tarascon, Nature, 2000, 407, 496-499.

2. J. M. Tarascon and M. Armand, Nature, 2001, 414, 359367.

3. B. Scrosati, J. Hassoun and Y.-K. Sun, Energy \& Environmental Science, 2011, 4, 3287-3295.

4. D. Bresser, E. Paillard, M. Copley, P. Bishop, M. Winter and S. Passerini, Journal of Power Sources, 2012, 219, 217-222.

5. R. Mukherjee, R. Krishnan, T.-M. Lu and N. Koratkar, Nano Energy, 2012, 1, 518-533.

6. G. G. Eshetu, S. Grugeon, G. Gachot, D. Mathiron, M Armand and S. Laruelle, Electrochimica Acta, 2013, 102, 133-141.

7. J. B. Goodenough and K.-S. Park, Journal of the American Chemical Society, 2013, 135, 1167-1176.

8. M. Winter and J. r. O. Besenhard, Electrochimica Acta, 1999, 45, 31-50.

9. S. Naille, C. M. Ionica-Bousquet, F. Robert, F. Morato, P. E. Lippens and J. Olivier-Fourcade, Journal of Power Sources, 2007, 174, 1091-1094.

$10 . \quad$ L. Bazin, S. Mitra, P. L. Taberna, P. Poizot, M. Gressier, M. J. Menu, A. Barnabé, P. Simon and J. M. Tarascon, Journal of Power Sources, 2009, 188, 578-582.

11. J. Hassoun, A. Fernicola, M. A. Navarra, S. Panero and B. Scrosati, Journal of Power Sources, 2010, 195, 574-579.

12. A. R. Kamali and D. J. Fray, Rev.Adv.Mater.Sci., 2011, 27, 14-24.

13. C. Mercier, R. Schneider, P. Willmann and D. Billaud, International Journal of Electrochemistry, 2011, 2011.

14. D. Bresser, F. Mueller, D. Buchholz, E. Paillard and S. Passerini, Electrochimica Acta, In Press, DOI: http://dx.doi.org/10.1016/j.electacta.2013.09.007.

15. H. Groult, H. El Ghallali, A. Barhoun, E. Briot, L. Perrigaud, S. Hernandorena and F. Lantelme, Electrochimica Acta, 2010, 55, 1926-1932.

16. H. Groult, H. El Ghallali, A. Barhoun, E. Briot, C. M. Julien, F. Lantelme and S. Borensztjan, Electrochimica Acta, 2011, 56, 2656-2664.

17. C. Petit and V. Repain, eds. D. Alloyeau, C. Mottet and C. Ricolleau, Springer Science edn., 2012, pp. 1-24.

18. C. Nayral, E. Viala, P. Fau, F. Senocq, J.-C. Jumas, A. Maisonnat and B. Chaudret, Chemistry - A European Journal, 2000, 6, 4082-4090.

19. Y. Wang, J. Y. Lee and T. C. Deivaraj, Journal of The Electrochemical Society, 2004, 151, A1804-A1809.

20. Á. Caballero, J. Morales and L. Sánchez, Electrochemical and Solid-State Letters, 2005, 8, A464-A466.

21. Y. Kwon, M. G. Kim, Y. Kim, Y. Lee and J. Cho, Electrochemical and Solid-State Letters, 2006, 9, A34A38.

22. S.-S. Chee and J.-H. Lee, Electron. Mater. Lett., 2012, 8, 587-593.

23. K. Kravchyk, L. Protesescu, M. I. Bodnarchuk, F. Krumeich, M. Yarema, M. Walter, C. Guntlin and M. V. Kovalenko, Journal of the American Chemical Society, 2013, DOI: 10.1021/ja312604r.

24. L. Balan, R. Schneider, J. Ghanbaja, P. Willmann and D. Billaud, Electrochimica Acta, 2006, 51, 3385-3390.

25. L. Balan, R. Schneider, P. Willmann and D. Billaud, Journal of Power Sources, 2006, 161, 587-593.
H. Zhang, H. Song, X. Chen and J. Zhou, The Journal of Physical Chemistry C, 2012, 116, 22774-22779.

28. J. Dupont, G. S. Fonseca, A. P. Umpierre, P. F. P. Fichtner and S. R. Teixeira, Journal of the American Chemical Society, 2002, 124, 4228-4229.

29. B. Léger, A. Denicourt-Nowicki, A. Roucoux and H. Olivier-Bourbigou, Advanced Synthesis \& Catalysis, 2008, 350, 153-159.

30. P. Dash and R. W. J. Scott, Chemical Communications, 2009, 0, 812-814

31. A. V. Mudring, T. Alammar, T. Bäcker and K. Richter, in Ionic Liquids: From Knowledge to Application, American Chemical Society, 2009, vol. 1030, ch. 12, pp. 177-188.

32. J. Dupont and J. D. Scholten, Chemical Society Reviews, 2010, 39, 1780-1804.

33. C. Vollmer and C. Janiak, Coordination Chemistry Reviews, 2011, 255, 2039-2057.

34. P. Arquillière, P. H. Haumesser and C. C. Santini, Microelectronic Engineering, 2012, 92, 149-151.

35. J. Dupont and M. R. Meneghetti, Current Opinion in Colloid \& Interface Science, 2013, 18, 54-60.

36. I. S. Helgadottir, P. P. Arquillière, P. Bréa, C. C. Santini, P. H. Haumesser, K. Richter, A. V. Mudring and M. Aouine, Microelectronic Engineering, In press, DOI: http://dx.doi.org/10.1016/j.mee.2012.09.015.

37. J. D. Scholten, G. Ebeling and J. Dupont, Dalton Transactions, 2007, 0, 5554-5560.

38. K.-S. Kim, D. Demberelnyamba and H. Lee, Langmuir, 2003, 20, 556-560.

39. H. Itoh, K. Naka and Y. Chujo, Journal of the American Chemical Society, 2004, 126, 3026-3027.

40. P. Singh, S. Kumar, A. Katyal, R. Kalra and R. Chandra, Materials Letters, 2008, 62, 4164-4166.

41. H. Zhang and H. Cui, Langmuir, 2009, 25, 2604-2612.
42. Y. Zhao, G. Cui, J. Wang and M. Fan, Inorganic Chemistry, 2009, 48, 10435-10441.

M. Brust, M. Walker, D. Bethell, D. J. Schiffrin and R. Whyman, Journal of the Chemical Society, Chemical Communications, 1994, DOI: 10.1039/C39940000801, 801-802.

44. A. Demortière and C. Petit, Langmuir, 2007, 23, 85758584

45. C. Salzemann and C. Petit, Langmuir, 2012, 28, 48354841.

46. P. Dash, S. M. Miller and R. W. J. Scott, Journal of Molecular Catalysis A: Chemical, 2010, 329, 86-95.

P. Bonhôte, A.-P. Dias, N. Papageorgiou, K. Kalyanasundaram and M. Grätzel, Inorganic Chemistry, 1996, 35, 1168-1178.

48. L. Gaillon, J. Sirieix-Plenet and P. Letellier, J Solution Chem, 2004, 33, 1333-1347.

49. J. Sirieix-Plénet, L. Gaillon and P. Letellier, Talanta, 2004, 63, 979-986.

Y. François, A. Varenne, J. Sirieix-Plenet and P. Gareil, Journal of Separation Science, 2007, 30, 751-760.

51. M. A. Vorotyntsev, V. A. Zinovyeva, D. V. Konev, M. Picquet, L. Gaillon and C. Rizzi, The Journal of Physical Chemistry B, 2009, 113, 1085-1099.

52. V. Lair, J. Sirieix-Plenet, L. Gaillon, C. Rizzi and A. Ringuedé, Electrochimica Acta, 2010, 56, 784-789. 
53. P. J. Chupas, X. Qiu, J. C. Hanson, P. L. Lee, C. P. Grey and S. J. L. Billinge, Journal of Applied Crystallography, 2003, 36, 1342-1347.

54. P. J. Chupas, P. L. Lee and K. W. Chapman, Journal of Applied Crystallography, 2007, 40, 463-470.

55. X. Qiu, J. W. Thompson and S. J. L. Billinge, Journal of Applied Crystallography, 2004, 37, 678-678.

56. C. L. Farrow, P. Juhas, J. W. Liu, D. Bryndin, E. S. Božin, J. Bloch, P. Th and S. J. L. Billinge, Journal of Physics: Condensed Matter, 2007, 19, 335219.

57. T. Egami and S. J. L. Billinge, eds., Underneath the Bragg Peaks: Structural Analysis of Complex Materials, Pergamon Press, Oxford, 2004.

58. A. A. H. Pádua, M. F. Costa Gomes and J. N. A. Canongia Lopes, Accounts of Chemical Research, 2007, 40, 10871096.

59. T. Gutel, C. C. Santini, K. Philippot, A. Padua, K. Pelzer, B. Chaudret, Y. Chauvin and J.-M. Basset, Journal of Materials Chemistry, 2009, 19, 3624-3631.

60. P. Migowski, D. Zanchet, G. Machado, M. A. Gelesky, S. R. Teixeira and J. Dupont, Physical Chemistry Chemical Physics, 2010, 12, 6826-6833.

61. T. Gutel, J. Garcia-Anton, K. Pelzer, K. Philippot, C. C. Santini, Y. Chauvin, B. Chaudret and J.-M. Basset, Journal of Materials Chemistry, 2007, 17, 3290-3292.

62. J. N. A. Canongia Lopes and A. A. H. Pádua, The Journal of Physical Chemistry B, 2006, 110, 3330-3335.

63. K. Shimizu, M. F. Costa Gomes, A. A. H. Pádua, L. P. N. Rebelo and J. N. Canongia Lopes, Journal of Molecular Structure: THEOCHEM, 2010, 946, 70-76.

64. R. L. Gardas, M. G. Freire, P. J. Carvalho, I. M. Marrucho, I. M. A. Fonseca, A. G. M. Ferreira and J. A. P. Coutinho, Journal of Chemical \& Engineering Data, 2007, 52, 18811888.

65. E. Redel, R. Thomann and C. Janiak, Inorganic Chemistry, 2007, 47, 14-16.

66. R. L. Gardas, H. F. Costa, M. G. Freire, P. J. Carvalho, I. M. Marrucho, I. M. A. Fonseca, A. G. M. Ferreira and J. A. P. Coutinho, Journal of Chemical \& Engineering Data, 2008, 53, 805-811.

67. S. Ernst, L. Aldous and R. G. Compton, Chemical Physics Letters, 2011, 511, 461-465.

68. Y. Hatakeyama, M. Okamoto, T. Torimoto, S. Kuwabata and K. Nishikawa, The Journal of Physical Chemistry C, 2009, 113, 3917-3922. 